\title{
DIVERSIDADE E DISTRIBUIÇÃO DE ESPÉCIES ARBÓREAS EM DUAS MATAS DE GALERIA NA MICRO-BACIA DO RIACHO FUNDO, DISTRITO FEDERAL
}

\author{
Alexandre Bonesso Sampaio' \\ Bruno Machado Teles Walter ${ }^{2}$ \\ Jeanine Maria Felfili ${ }^{3}$
}

Recebido em 27/07/1999. Aceito em 15/03/2000

\begin{abstract}
RESUMO - (Diversidade e distribuição de espécies arbóreas em duas Matas de Galeria na micro-bacia do Riacho Fundo, Distrito Federal). As Matas de Galeria representam uma formação florestal típica do cerrado, que acompanha cursos d'água de pequeno porte. Variações locais na florística e na fitossociologia dessas matas parecem estar correlacionadas principalmente com a topografia, grau de encharcamento do solo e luminosidade. Haveria maior similaridade florística e estrutural entre trechos de matas diferentes, sob condições abióticas semelhantes, do que entre trechos de uma mesma mata sob condições abióticas distintas? Para responder a esta pergunta foram comparadas as comunidades arbóreas das matas de galeria do córrego Riacho Fundo e Açudinho, Distrito Federal, ambas pertencentes à mesma micro-bacia hidrográfica. Nestas duas matas foram estabelecidas linhas de amostragem perpendiculares ao córrego, totalizando 118 parcelas de 10x20m (2,36ha). Foram amostrados todos os indivíduos com DAP $\geq 5 \mathrm{~cm}$, exceto lianas. A amostragem no Riacho Fundo incluiu 1.831 indivíduos vivos (1,58ha, 150 spp., $\left.\mathrm{H}^{\prime}=4,15\right)$ e no Açudinho $1.228\left(0,78 \mathrm{ha}, 126 \mathrm{spp} ., \mathrm{H}^{\prime}=4,25\right)$. Os resultados indicaram que as variaçōes florísticas e estruturais encontradas entre estas matas podem ser explicadas principalmente pelas condições abióticas, particulares à cada uma delas. Trechos de cada mata que possuem condições ambientais semelhantes foram mais similares entre si do que trechos contíguos na mesma mata, sob condições diferentes, conforme foi verificado pela classificação por TWINSPAN. As condições de drenagem do solo, as fitofisionomias adjacentes e o histórico de perturbação foram os principais fatores determinantes dos agrupamentos.
\end{abstract}

Palavras-chave - mata de galeria, estrutura, florística, similaridade, cerrado

\begin{abstract}
Diversity and distribution of arboreal species in two gallery forests in the "Riacho Fundo" hydrographic basin, Distrito Federal). Local variation in the floristic composition and structure of gallery forests seems to be related to slope, soil humidity and light. Would the floristic similarity between patches of different forests under similar abiotic conditions be higher than the similarity between patches of the same forest under different conditions? "Riacho Fundo" and "Açudinho" gallery forests were compared in order to answer this question. Both forests belong to the "Riacho Fundo" hydrographic basin. Sampling was systematic with sampling lines perpendicular to the main stream. A total of 118 plots $(10 \times 20 \mathrm{~m}$ each) placed along these lines were assessed. All individuals from $5 \mathrm{~cm}$ DBH, except lianas, were measured. In "Riacho Fundo" there were 1,831 living individuals (1.58ha sampled, 150 spp., H' = 4.15) and in "Açudinho" there were 1,228 living individuals ( 0.78 ha sampled, 126
\end{abstract}

1 Universidade de Brasília, Departamento de Ecologia, Brasília, DF, Brasil. e-mail: bonesso@ cenargen.embrapa.com.br

2 EMBRAPA Recursos Genéticos e Biotecnologia, Brasilia, DF, Brasil. e-mail: bwalter@ cenargen.embrapa.com.br

Universidade de Brasília, Departamento de Engenharia Florestal, C. Postal 04357, CEP 70919-970, Brasília, DF, Brasil 
spp., $H^{\prime}=4.25$ ). Results seem to indicate that the floristic and structural differences between these forests can be explained by the abiotic conditions, peculiar to each one. According to TWINSPAN divisions, certain patches of different forests that occur under similar abiotic conditions are more similar amongst themselves than to patches of the same forest under different conditions. Water availability in the soil, adjacent vegetation types and disturbance history seem to be the main determinants of the groupings.

Key words - gallery forest, structure, floristic, similarity, Brazil

\section{Introdução}

No bioma Cerrado há formações savânicas e campestres que predominam nas áreas de interflúvios, enquanto que um tipo de formação florestal, denominado "mata de galeria", acompanha os cursos d'água de pequeno porte. Estas matas formam uma rede que parece conectar as Florestas Amazônica e Atlântica, no sentido noroeste-sudeste, atravessando o Cerrado como se fossem corredores de migração de espécies (Rizzini 1979; Oliveira-Filho \& Ratter 1995). As matas de galeria estão sujeitas à influência de diferentes floras, oriundas de formas e tipos de vegetação distintos, que ocasionam grandes variações locais devidas ao clima, à latitude e aos fatores edáficos. Como resultado, há uma composição florística extremamente diversa (Oliveira-Filho \& Ratter 1995; Walter \& Ribeiro 1997; Ribeiro \& Walter 1998, Silva Jr. et al. 1998), comparável à áreas das Florestas Amazônica e Atlântica (Felfili 1995). Formas de vegetação similares, como nas florestas galeria de Belize, também mantém alta diversidade de espécies, semelhante àquela encontrada nas florestas tropicais contínuas daquele país (Kellman et al. 1996).

Em comunidades florestais, a heterogeneidade espacial do ambiente físico tende a ser fator importante na coexistência de espécies arbóreas (Fowler 1988) e, conseqüentemente, na manutenção da diversidade de espécies (Huston 1979). A heterogeneidade ambiental, ou outros fatores locais considerados isoladamente, podem não explicar totalmente a diversidade de espécies, pois processos regionais e históricos também agem nas comunidades (Ricklefs 1987). Em escala local, condições abióticas como disponibilidade de água, topografia e luz têm sido apontadas como os principais fatores condicionantes das matas de galeria (OliveiraFilho 1989; Schiavini 1992; Oliveira-Filho et al. 1994; Felfili 1995, 1998; Silva Jr. 1995; Walter 1995; Haridasan et al. 1997; Rezende et al. 1997).

Ao estudarem matas de galeria no Distrito Federal (DF), Felfili et al. (1994), Felfili (1995; 1998), Silva Jr. (1995) e Walter (1995) distinguiram associações de espécies decorrentes da preferência de determinadas espécies por locais com solos mal drenados (inundáveis) ou bem drenados, e ainda com diferentes níveis de cobertura do dossel. Vários autores, como Felfili et al. (1994), Oliveira-Filho \& Ratter (1995), Walter (1995) e Rezende et al. (1997), ao compararem diferentes matas de galeria, sugeriram que mesmo matas próximas poderiam apresentar composição florística bastante distinta, dependendo das condições ambientais predominantes em cada uma delas.

Também localizada no DF, a mata de galeria do córrego Açudinho foi recentemente estudada por Sampaio et al. (1997). Estes autores encontraram variações florísticas e estruturais entre e dentro dos três trechos que estudaram naquela mata. As variações na comunidade arbórea foram atribuídas principalmente às mudanças locais na condição de drenagem do solo. Os resultados deste estudo, e dos demais anteriormente citados, indicaram que as matas de galeria podem representar um mosaico de vegetação, formado por sub-unidades das comunidades arbóreas, com limites muitas vezes bastante distintos.

A partir do conhecimento atual sobre a distribuição de espécies arbóreas nas matas de ga- 
leria, pode-se formular a seguinte pergunta: trechos de duas matas distintas, sob condições abióticas semelhantes, poderiam ser mais similares florística e estruturalmente do que trechos contíguos de uma única mata, sob condições abióticas diferentes? Objetivando responder esta questão, a comunidade arbórea da mata de galeria do córrego Riacho Fundo (DF) foi estudada e comparada com a mata do córrego Açudinho, contígua à do Riacho Fundo, e que foi anteriormente estudada por Sampaio et al. (1997).

\section{Material e métodos}

Local do estudo - O estudo foi realizado na mata de galeria (sensu Ribeiro \& Walter 1998) do córrego Açudinho e no trecho da mata de galeria do córrego Riacho Fundo, compreendidas na Fazenda Sucupira (FAZ), Distrito Federal. Estas matas são interligadas e ambas pertencem ao que se denomina microbacia do Riacho Fundo (Fig. 1).

A FAZ está localizada entre as coordenadas $15^{\circ} 52^{\prime}$ a $15^{\circ} 56^{\prime} \mathrm{S}$ e $48^{\circ} 00^{\prime}$ a $48^{\circ} 02^{\prime} \mathrm{W}$, à sudeste da cidade de Brasília, e conta com área de cerca de 1.700 ha (Fig. 1). Esta Fazenda é circundada parcialmente pela Chapada da Contagem e tem a maior parte de sua área incluída na Depressão do Paranoá (Pinto 1994). Nesta unidade geomorfológica estão localizados os córregos Riacho Fundo e Açudinho. O córrego Açudinho é afluente do Riacho Fundo, o qual drena para a bacia hidrográfica do rio São Bartolomeu, que se vincula à grande bacia Platina (Walter \& Sampaio 1998).

A fitofisionomia mata de galeria engloba cerca de 153 ha da área total da FAZ, sendo o trecho do Riacho Fundo o maior fragmento florestal, ocupando $79 \mathrm{ha}(8,2 \mathrm{~km}$ de perímetro). Esse fragmento apresenta sua maior parte bem preservada, ainda que ocorram alguns locais com perturbações antrópicas. Estes locais são representados por duas grandes clareiras de origem antrópica, das quais uma apresenta-se em estádio de regeneração natural e a outra é ocupada por habitações de moradores da FAZ (nas proximidades da confluência dos córregos Açudinho e Riacho Fundo - Fig. 1). Além destes, uma estrada vicinal divide as matas do Riacho Fundo e Açudinho (Walter \& Sampaio 1998).

A Mata do Açudinho está totalmente inclusa na FAZ e ocupa $28 \mathrm{ha}$ ( $5 \mathrm{~km}$ de perímetro). Esta mata apresenta-se em bom estado de conservação, embora seja entrecortada por duas barragens para captação de água e pela estrada acima referida (Fig. 1).

Amostragem da comunidade arbórea - $\mathrm{Na}$ mata do córrego Riacho Fundo foi realizada amostragem sistemática, em 79 parcelas de $10 \mathrm{~m}$ x $20 \mathrm{~m}\left(200 \mathrm{~m}^{2}\right)$, totalizando 1,58 ha de área amostral. As parcelas foram dispostas de forma contígua, compondo três linhas de amostragem (transecto) perpendiculares ao leito do córrego. Cada linha atravessou a mata de uma borda à outra. A linha de amostragem L1 ficou localizada mais próxima à confluência do córrego Açudinho com o córrego Riacho Fundo; a linha L2 atravessou a grande clareira em regeneração (parcelas 37 a 47), acima citada; e a linha L3 ficou próxima da divisa noroeste da FAZ, na porção mais alta e mais larga desta mata (Fig 1). A linha L1 comportou as parcelas de números 1 a 30; L2, parcelas 31 a 50; e L3, parcelas de 51 a 79 (Fig. 1).

$\mathrm{Na}$ mata do Açudinho a amostragem também foi dividida em três trechos, que comportaram 39 parcelas $(0,78 \mathrm{ha})$. Estes trechos foram denominados por Sampaio et al. (1997): Cabeceira (duas linhas de amostragem ( $\mathrm{C} 1$ e C2), com sete parcelas cada - parcelas de números 80 a 94); Porção Central (três linhas (M1, M2 e M3), com quatro parcelas cada - parcelas 95 a 106); e Final (uma linha (F1), com treze parcelas - de números 107 a 118) (Fig. 1).

Nas duas matas foram incluídos na amostragem todos os indivíduos arbóreos, cujo diâmetro a altura do peito (DAP) fosse igual ou maior que $5 \mathrm{~cm}$ (lianas excluídas). Todos os indivíduos amostrados foram marcados com pla- 


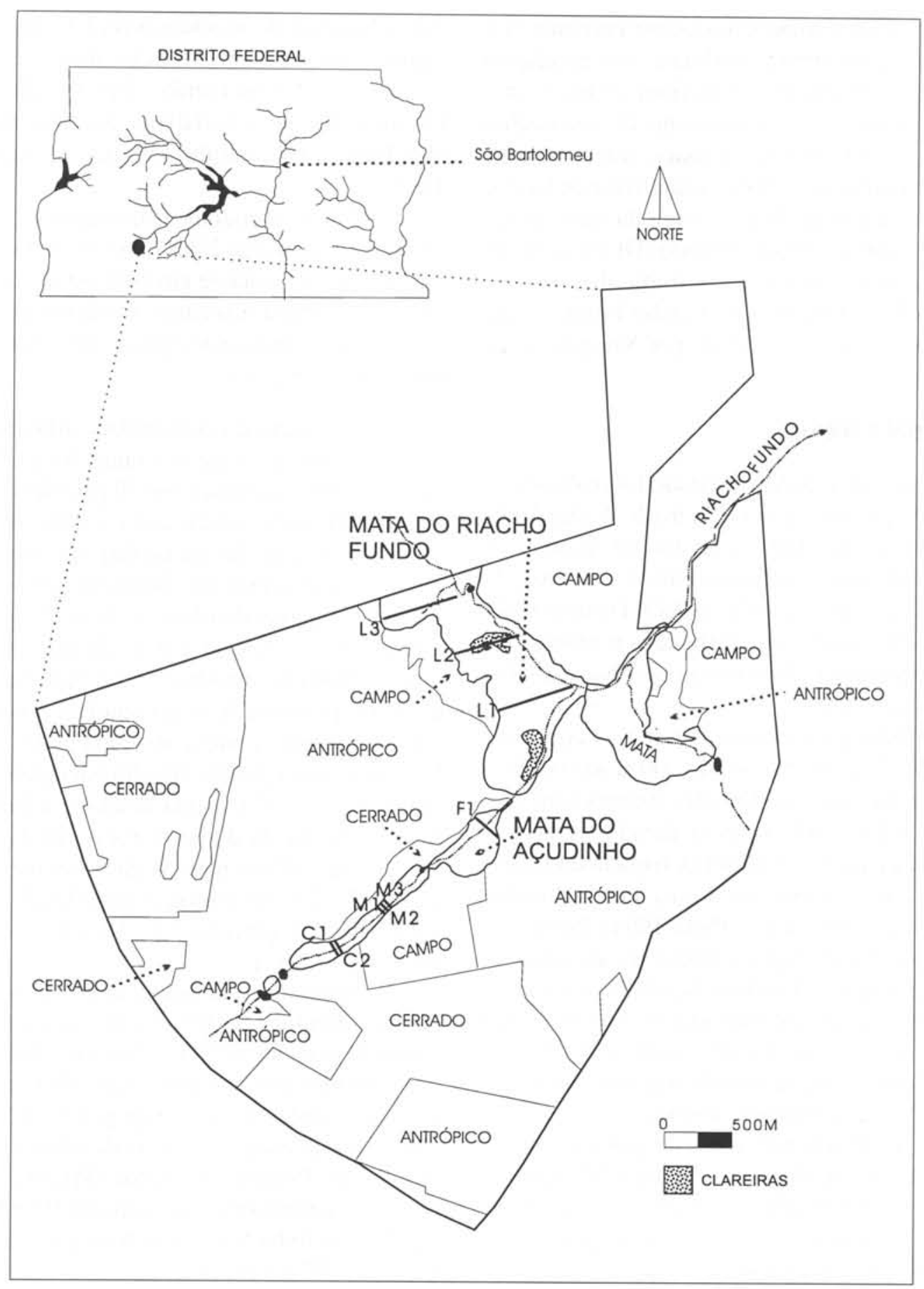

Figura 1. Mapa de vegetação da Fazenda Sucupira, Distrito Federal. Destaque para as matas de galeria dos córregos Açudinho e Riacho Fundo, e suas respectivas linhas amostrais (C1, C2, M1, M2, M3, F1 - Mata do Açudinho; L1, L2, L3 - Mata do Riacho Fundo). 
cas metálicas para futuras medições e para certificação posterior das identificações. Para todos os indivíduos foram medidos os DAP's e a altura total. Todas as espécies encontradas foram coletadas, mesmo aquelas em que não foi possível a obtenção de espécimes com flores. Estes materiais testemunhos estão depositados no herbário do CENARGEN (CEN).

Descrição do ambiente nas parcelas - $\mathrm{O}$ trecho da mata do Riacho Fundo presente na FAZ possui em toda sua extensão cerca de $600 \mathrm{~m}$ de largura, o que é bastante superior à situação encontrada na mata do Açudinho, que varia de $80 \mathrm{~m}$ a, no máximo, 300m (Fig. 1). Esses fragmentos de mata de galeria distinguem-se em termos de área e largura, além de possuírem perímetros também distintos. A mata do Açudinho faz interface com maior diversidade de fisionomias, entre as quais diferentes subtipos de Cerrado sentido restrito (Fig. 1), além de áreas de Campo Sujo Úmido e uma mancha de Vereda (sensu Ribeiro \& Walter 1998). A mata do Riacho Fundo, por sua vez, está em contato apenas com áreas de Campo Sujo Seco e pequenas manchas de Cerrado Típico (Fig. 1).

O córrego Riacho Fundo é um curso d'água com calha profunda, bem definida, e de leito mais largo do que a calha de seu tributário, o córrego Açudinho. O córrego Riacho Fundo também caracteriza-se pela presença de meandros bem definidos, o que não se verifica no Açudinho.

Sendo o leito do córrego Riacho Fundo mais profundo e a cobertura de mata mais larga, de maneira geral, a mata de galeria associada está condicionada a solos bem drenados. Portanto, esta mata pode ser classificada como mata de galeria não-inundável (Ribeiro \& Walter 1998). Ainda assim há trechos em solos mal drenados (parcelas 41, 48, 49, 68, 69, 70, 71), condicionados principalmente pela presença de pequenos tributários. Apenas a parcela 49 sofre influência direta do curso d'água principal. Em contrapartida, na mata do Açudinho são encon- tradas tanto parcelas em solos bem drenados, como em solos mal drenados, dependendo da topografia e da proximidade com o curso d'água principal. Conforme Sampaio et al. (1997), a mata do Açudinho não se adequa perfeitamente aos sub-tipos de mata de galeria (inundável e não-inundável), propostos por Ribeiro \& Walter (1998).

A maior homogeneidade nas condições abióticas da mata do Riacho Fundo é interrompida apenas pela presença da grande clareira (parcelas 37 a 47 da linha L2 - Fig. 1), e pelos referidos tributários que nascem no interior da mata, nas linhas L2 e L3 (Fig. 1). A grande clareira apresenta locais com vegetação florestal em estádio avançado de regeneração secundária, mas ainda com dossel mal definido. Conforme fotos aéreas de 1960, ano da inauguração de Brasília, naquela época o solo estava exposto e não havia árvores ou arbustos no local, o que indica origem antrópica para esta clareira. Por outro lado, na linha L1 (Fig. 1) não existem clareiras e tampouco cursos d’água em afloramento, exceto pelo próprio córrego Riacho Fundo.

As variações topográficas na mata do Açudinho são mais acentuadas que as encontradas no Riacho Fundo. As linhas de amostragem da Cabeceira do Açudinho posicionaram-se sobre grande declividade do terreno, onde as parcelas próximas ao córrego encontram-se em locais mal drenados. As linhas da Porção Central posicionaram-se em terreno com declividade pouco acentuada, e muitas parcelas $(94,95,98$, $99,102,103$ ) sofrem forte influência do córrego mal definido, o qual não constitui dreno eficiente naquele local. Na linha do trecho Final, apesar da declividade suave em relação aos outros trechos, os solos são bem drenados, pois o córrego neste trecho é bem definido, largo e profundo, propiciando drenagem mais eficiente. Neste trecho, a situação encontrada é a mesma que predomina no contíguo Riacho Fundo. Assim, a topografia irregular e as características abióticas do vale do Açudinho proporcionam 
condições mais heterogêneas que as encontradas como padrão no trecho estudado da mata do Riacho Fundo.

Análise dos dados - A diversidade florística das matas de galeria estudadas foi avaliada pelos índices de Shannon (H'- diversidade) e Pielou (J'- equabilidade) na base logarítmica neperiana (Margurran 1988).

Para analisar a distribuição e verificar a possível existência de associações de espécies arbóreas, foi realizada uma classificação das parcelas estudadas pelo método TWINSPAN ("Two Way Indicator Species Analysis") (Hill et al. 1975; Hill 1979). Esta classificação permite inferir sobre eventuais relações bióticas com as variáveis ambientais nas comunidades estudadas (Kent \& Coker 1995).

O TWINSPAN realiza classificação da vegetação por meio de dicotomizações sucessivas, pelas espécies em função das parcelas em que estas ocorrem, e pelas parcelas em função das espécies que nelas ocorrem (Hill et al. 1975). Esta análise multivariada permite identificar a existência de relações hierárquicas entre as associações de espécies que compõem sub-unidades dentro das comunidades.

As parcelas das matas do Açudinho e Riacho Fundo foram organizadas em uma matriz única, para verificar a possível ocorrência de grupos de parcelas independentes das distâncias físicas entre elas. Foram realizadas três análises por TWINSPAN, cada qual utilizando dados de presença ou ausência das espécies nas parcelas; densidade; e área basal das espécies. Dessa forma foram analisados os padrões de associações de parcelas e espécies, em relação à florística e à estrutura das comunidades das matas estudadas.

Os dendrogramas gerados a partir das três análises por TWINSPAN foram avaliados quanto à inclusão de mais agrupamentos de parcelas explicáveis pelas condições bióticas ou abióticas. Adicionalmente, a análise que produziu menos parcelas mal classificadas foi considerada como a mais conveniente para identificar sub-unidades nas comunidades. Considerado então o dendrograma mais adequado, com dados de densidade das espécies, foram calculados parâmetros fitossociológicos para caracterizar a estrutura destas sub-unidades das comunidades arbóreas. Para verificar as diferenças entre os parâmetros fitossociológicos calculados para estas sub-unidades, ou grupos de parcelas, foi utilizada a estatística de KruskalWallis, teste não paramétrico que permite comparações entre populações amostrais com variâncias heterogêneas (Zar 1996).

\section{Resultados e discussão}

Riqueza e Diversidade - Na mata do Riacho Fundo foram amostrados 1.831 indivíduos vivos, distribuídos em 150 espécies, pertencentes a 55 famílias botânicas (Tab. 1). O Índice de Shannon (H') calculado foi de 4,15 nats/indivíduo. A riqueza em espécies e famílias encontradas nesta mata foi superior à encontrada na mata do Açudinho, onde foram amostradas 126 espécies em 50 famílias (Tab. 1). Entretanto, ainda que a comunidade arbórea do Riacho Fundo tenha apresentado maior riqueza em espécies que a do Açudinho, a mata do Açudinho é mais diversa $\left(H^{\prime}=4,25\right.$ nats/indivíduo), o que se deve ao componente equabilidade. A distribuição dos indivíduos por espécie foi mais uniforme no Açudinho $\left(\mathrm{J}^{\prime}=0,61\right)$ do que no Riacho Fundo $\left(\mathrm{J}^{\prime}=0,57\right)$. A maior diversidade encontrada na mata do Açudinho pode ser explicada pela maior heterogeneidade ambiental, além da influência de maior número de fitofisionomias com as quais faz interface.

As dez espécies mais importantes (Índice de Valor de Importância - IVI) do Riacho Fundo, em ordem decrescente, foram: Metrodorea stipularis, Cheiloclinium cognatum, Copaifera langsdorffii, Cryptocaria aschersoniana, Tapirira guianensis, Faramea cyanea, Tibouchina candolleana, Inga sp. 2, Alibertia sessilis, Inga sp. (Tab. 1). Na mata do Açudinho, as dez espécies mais importantes, indicadas por Sampaio et al. (1997), foram: Copaifera 
Tabela 1. Espécies amostradas nos levantamentos das matas de galeria dos córregos Açudinho (AC) e Riacho Fundo (RF), na Fazenda Sucupira, DF. Para cada espécie, ordenadas por famílias, estão apresentados o número de indivíduos (N), a densidade (DENS) por hectare, a dominância (DOM) em m²/ha, a posição (POS) em IVI (Índice de Valor de Importância), e o ambiente (Hab) preferencial de cada espécie (U - locais com solo mal drenado; S - locais com solo bem drenado; $\mathrm{Ce}$ - ecótono mata/cerrado; $\mathrm{Ms}$ - locais similares à mata seca; $\mathrm{Cl}$ - locais na grande clareira do Riacho Fundo; $\mathrm{O}$ - espécies que não são exclusivas de nenhum tipo de ambiente).

Familia

Hab

Espécie

$\frac{\mathrm{N}}{\mathrm{AC} \quad \mathrm{RF}} \quad \frac{\mathrm{DENS}}{\mathrm{AC} \quad \mathrm{RF}} \frac{}{\mathrm{AC} \quad \mathrm{RF}} \frac{\mathrm{POS}}{\mathrm{AC} \quad \mathrm{RF}}$

Anacardiaceae

Astronium fraxinifolium Schott.

Lithrea molleoides (Vell.) Engl.

Tapirira guianensis Aubl.

\section{Annonaceae}

Cardiopetalum calophyllum Schlecht.

Guatteria sellowiana Schlecht.

Unonopsis lindmanii R. E. Fries

Xylopia emarginata Mart.

$X$. sericea A. St.-Hil.

\section{Apocynaceae}

Aspidosperma cylindrocarpon Müll. Arg.

A. discolor A. DC.

A. spruceanum Benth ex. Müll. Arg.

A. subincanum Mart.

\section{Aquifoliaceae}

llex conocarpa Reiss.

I. integrifolia Hort. ex Gard.

Aquifoliaceae (Indeterminada 1)

Araliaceae

Dendropanax cuneatum (DC.)

Decne \& Planch.

Schefflera morototonii (Aubl.)

B. Maguire, Steyerm \& D. C. Frodin

Bignoniaceae

Jacaranda cf. brasiliana (Lam.) Pers.

Tabebuia roseo-alba (Ridley) Sandw.

\section{Bombacaceae}

Chorisia pubiflora (St.-Hil) Dawson

Eriotheca gracilipes (K. Schum.) A. Robyns. O

Pseudobombax longiflorum (Mart. \& Zucc.)

\section{Boraginaceae}

$$
\text { A. Robyns. }
$$

$\begin{array}{lrr}\mathrm{O} & 1 & 15 \\ \mathrm{O} & 1 & 2 \\ \mathrm{U} & 48 & 63\end{array}$

1,28
1,28
61,54

0,00
14,10
0,00
30,77
12,82

$\begin{array}{rr}9,49 & 0,099 \\ 1,27 & 0,010 \\ 39,87 & 1,445\end{array}$

$0,136 \quad 101$

33

\begin{tabular}{lllllllll}
\hline & 0 & 1 & 0,00 & 0,63 & 0,000 & 0,008 & - & 129
\end{tabular}

$\begin{array}{llllll}\mathrm{O} & 11 & 6 & 14,10 & 3,80 & 0,224\end{array}$

$\begin{array}{llll}0 & 0 & 1 & 0,00\end{array}$

U 24

$0,63 \quad 0,000$

$0,00 \quad 0,330$

$2,53 \quad 0,114$

$0,022 \quad 116$

107

U 10

12,82

O $\quad 0 \quad 5 \quad 0,00$

$\begin{array}{lll}0 & 9 & 7\end{array}$

11,54

$3,17 \quad 0,000$

$\begin{array}{lll}0,041 & 34 & 72\end{array}$

O 0

0,00

$\begin{array}{ll}4,43 & 0,229\end{array}$

14,10

$1,27 \quad 0,000$

$0,007 \quad-131$

$\begin{array}{lll}\text { S } & 11 \quad 33\end{array}$

$20,89 \quad 0,470$

$0.000 \quad 26$

$0,032 \quad 36 \quad 86$

$\begin{array}{llll}\mathrm{Ce} & 8 & 1 & 10,26\end{array}$

$0,63 \quad 0,361$

U 21

26,92

$0,00 \quad 0,205$

$0,273-48$

$\begin{array}{lll}0,056 & 44 & 68\end{array}$

$\begin{array}{llll}\mathrm{O} & 0 & 1 & 0,00\end{array}$

$0,630,000$

$0,024-104$

$0,484 \quad 30 \quad 15$

Cordia cf. sellowiana Cham.

\section{Burseraceae}

Protium almecega March.

P. heptaphyllum (Aubl.) March.

$\begin{array}{lll}\mathrm{O} & 1 & 1\end{array}$

1,28

$0,63 \quad 0,011$

$0,024 \quad 115$

118

U 13

16,67

$2,53 \quad 0,106$

$0,228 \quad 38$

59

$\begin{array}{llll}\mathrm{Ce} & 5 & 1 & 6,41\end{array}$

$\begin{array}{ll}0,63 & 0,070\end{array}$

$\begin{array}{lll}0,007 & 67 & 130\end{array}$

Ms $9 \quad 8 \quad 11,54$

$5,06 \quad 0,162$

$0,113 \quad 55 \quad 58$

$\begin{array}{llll}\mathrm{O} & 0 & 1 & 0,00\end{array}$

$0,63 \quad 0,000$

$0,002 \quad-143$

1,28

$3,17 \quad 0,316$

0,064

63

$0,00 \quad 0,023$

$0,000 \quad 82$

$\begin{array}{llll}0 & 6 & 6 & 7,69\end{array}$

$3,80 \quad 0,261$

0,05

43

62,82

$5,06 \quad 1,026$

0,128

84,62

$12,66 \quad 1,206$

0,399

65

Caryocaraceae

Caryocar brasiliense Camb.

\section{Cecropiaceae}

Cecropia cf. pachystachia Tréc.

\section{Celastraceae}

Maytenus alaternoides Reiss.

O 2

2,56

$0,00 \quad 0,016$

$0,000 \quad 108$

$\begin{array}{lll}\text { Cl } & 0 & 19\end{array}$

0,00

$12,03 \quad 0,000$

$0,062-$

O $\quad 0 \quad 1$

0,00

$0,63 \quad 0,000$

0,019 - 
Tabela 1. (continuação)

Família Espécie
$\mathrm{Hab}$ $\frac{\mathrm{N}}{\mathrm{AC} \quad \mathrm{RF}} \frac{\mathrm{DENS}}{\mathrm{AC} \quad \mathrm{RF}} \frac{\mathrm{DOM}}{\mathrm{AC} \quad \mathrm{RF}} \frac{\mathrm{POS}}{\mathrm{AC} \text { RF }}$

Chloranthaceae

Hedyosmum brasiliense Mart. ex Miq.

\section{Chrysobalanaceae}

Licania apetala (E. Meyer) Fritsch.

Licania sp.

Chrysobalanaceae (Indeterminada 1)

\section{Combretaceae}

Terminalia argentea Mart. \& Zucc.

T. glabrescens Mart.

\section{Compositae}

Eupatorium sp.

Piptocarpha macropoda (DC.) Baker

\section{Cunnoniaceae}

Lamanonia ternata Vell.

\section{Cyatheaceae}

Cyathea sp.

Dichapetalaceae

Tapura amazonica Poepp. \& Endl.

\section{Ebenaceae}

Diospyros cf. hispida A. DC.

\section{Elaeocarpaceae} Sloanea guianensis (Aubl.) Benth.

\section{Erythroxylaceae}

Erythroxylum daphnites Mart.

Erythroxylaceae (Indeterminada 1)

\section{Euphorbiaceae}

Alchornea iricurana Casar.

Hyeronima alchorneoides Fr. Allem.

Maprounea guianensis (Aubl.) Müll. Arg.

Pera glabrata (Schott.) Baill.

Richeria grandis Vahl.

Sapium sp.

\section{Flacourtiaceae}

Casearia sylvestris $\mathrm{Sw}$.

Xylosma sp.

\section{Guttiferae}

Calophyllum brasiliense Camb.

Clusia sp.

\section{Guttiferae}

Rheedia sp.

Vismia sp.

Hippocrateaceae

Cheiloclinium cognatum (Miers.) A.C. Smith

Salacia elliptica (Mart.) G. Don.

\section{Humiriaceae}

Sacoglottis guianensis Benth.

\section{Icacinaceae}

Emmotum nitens (Benth.) Miers.

\section{Indeterminada}

Indeterminada 1

$\begin{array}{rrrrrrrrr}\mathrm{Cl} & 0 & 13 & 0,00 & 8,23 & 0,000 & 0,044 & - & 56 \\ & & & & & & & & \\ \mathrm{U} & 39 & 35 & 50,00 & 22,15 & 1,112 & 0,743 & 5 & 11 \\ \mathrm{O} & 3 & 0 & 3,85 & 0,00 & 0,057 & 0,000 & 87 & - \\ \mathrm{O} & 5 & 0 & 6,41 & 0,00 & 0,061 & 0,000 & 58 & -\end{array}$

$\begin{array}{lllllllll}\text { Ms } & 1 & 17 & 1,28 & 10,76 & 0,004 & 1,058 & 120 & 14\end{array}$

$\begin{array}{lllllllll}\mathrm{S} & 11 & 20 & 14,10 & 12,66 & 1,458 & 0,666 & 9 & 16\end{array}$

$\begin{array}{lllllllll}\mathrm{O} & 0 & 1 & 0,00 & 0,63 & 0,000 & 0,002 & - & 145\end{array}$

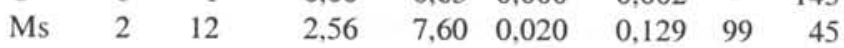

$\begin{array}{lllllllll}\text { Ce } & 11 & 2 & 14,10 & 1,27 & 0,707 & 0,142 & 22 & 83\end{array}$

$\begin{array}{lllllllll}\mathrm{U} & 26 & 16 & 33,33 & 10,13 & 0,241 & 0,066 & 20 & 46\end{array}$

$\begin{array}{lllllllll}\mathrm{O} & 4 & 8 & 5,13 & 5,06 & 0,055 & 0,040 & 65 & 63\end{array}$

$\begin{array}{lllllllll}\text { Ms } & 4 & 30 & 5,13 & 18,99 & 0,063 & 0,229 & 79 & 23\end{array}$

$\begin{array}{lllllllll}\mathrm{O} & 0 & 1 & 0,00 & 0,63 & 0,000 & 0,003 & - & 137\end{array}$

$\begin{array}{lllllllll}\mathrm{O} & 2 & 5 & 2,56 & 3,17 & 0,106 & 0,024 & 92 & 96\end{array}$

$\begin{array}{llllllll}\mathrm{Ce} & 8 & 0 & 10,26 & 0,00 & 0,163 & 0,000 & 40\end{array}$

$\begin{array}{lllllllll}\mathrm{O} & 0 & 3 & 0,00 & 1,90 & 0,000 & 0,055 & - & 88\end{array}$

$\begin{array}{lllllllll}\mathrm{U} & 6 & 8 & 7,69 & 5,06 & 0,109 & 0,146 & 61 & 51\end{array}$

$\begin{array}{lllllllll}\mathrm{U} & 18 & 6 & 23,08 & 3,80 & 0,619 & 0,114 & 17 & 71\end{array}$

$\begin{array}{lllllllll}\mathrm{Ce} & 13 & 12 & 16,67 & 7,60 & 0,437 & 0,198 & 27 & 34\end{array}$

$\begin{array}{lllllllll}\mathrm{U} & 39 & 0 & 50,00 & 0,00 & 1,237 & 0,000 & 8 & -\end{array}$

$\begin{array}{lllllllll}\mathrm{O} & 0 & 4 & 0,00 & 2,53 & 0,000 & 0,027 & - & 87\end{array}$

$\begin{array}{lllllllll}\mathrm{O} & 0 & 8 & 0,00 & 5,06 & 0,000 & 0,070 & - & 55\end{array}$

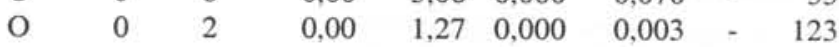

$\begin{array}{lllllllll}\mathrm{U} & 6 & 15 & 7,69 & 9,49 & 1,062 & 0,284 & 19 & 67\end{array}$

$\begin{array}{llllllll}\mathrm{O} & 2 & 0 & 2,56 & 0,00 & 0,018 & 0,000 & 102\end{array}$

$\begin{array}{lllllllll}\text { Ms } & 4 & 11 & 5,13 & 6,96 & 0,062 & 0,198 & 72 & 36\end{array}$

$\begin{array}{lllllllll}\mathrm{O} & 0 & 1 & 0,00 & 0,63 & 0,000 & 0,002 & - & 146\end{array}$

$\begin{array}{lllllllll}\mathrm{S} & 31 & 119 & 39,74 & 75,32 & 0,610 & 1,612 & 13 & 2\end{array}$

$\begin{array}{lllllllll}\mathrm{S} & 9 & 19 & 11,54 & 12,03 & 0,152 & 0,134 & 46 & 26\end{array}$

$\begin{array}{lllllllll}\mathrm{O} & 6 & 3 & 7,69 & 1,90 & 0,135 & 0,341 & 51 & 47\end{array}$

$\begin{array}{lllllllll}\mathrm{Ce} & 17 & 5 & 21,80 & 3,17 & 0,639 & 0,067 & 15 & 82\end{array}$

$\begin{array}{lllllllll}\mathrm{O} & 0 & 1 & 0,00 & 0,63 & 0,000 & 0,002 & - & 138\end{array}$ 
Tabela 1. (continuação)

Familia Espécie
$\mathrm{Hab}$

$\frac{\mathrm{N}}{\mathrm{AC} \quad \mathrm{RF}}$ $\frac{\text { DENS }}{\mathrm{AC} \quad \mathrm{RF}}$

$\frac{\mathrm{DOM}}{\mathrm{AC} \quad \mathrm{RF}}$
$\frac{\text { POS }}{\mathrm{AC} \quad \mathrm{RF}}$

\section{Indeterminada}

Indeterminada 2

\section{Lauraceae}

Aionea sp.

Aniba heringerii Vatt.

Cryptocaria aschersoniana $\mathrm{Mez}$

Endlicheria paniculata (Spreng.) Macbr.

Nectandra sp.

Ocotea aciphylla (Ness) Mez

$O$. puchella Mart.

O. spixiana (Ness) Mez

Lauraceae (Indeterminadal)

\section{Lecythidaceae}

Cariniana estrellensis (Raddi) Kuntze

\section{Leguminosae}

Acacia polyphylla DC.

Acosmium sp.

Anadenanthera colubrina (Vell.) Brenan

Anadenanthera sp.

Andira sp.

Apuleia leiocarpa (Vog.) Macbr.

Bauhinia rufa (Bong.) Steud.

Centrolobium tomentosum Guill. ex. Benth.

Copaifera langsdorffii Desf.

Dalbergia densiflora Benth.

D. miscolobium Benth.

Hymenaea courbaril L. var. courbaril

Inga cf. alba (Sw.) Willd.

Inga cf. ingoides (Rich.) Willd.

Inga sp. 1

Inga sp. 2

Lonchocarpus sp.

Machaerium acutifolium Vog.

Machaerium sp.

Ormosia sp.

Piptadenia gonoacantha (Mart.) Macbr.

Platymiscium floribundum Vog.

Platypodium elegans Vog.

Sclerolobium aureum (Tul.) Benth.

$S$. paniculatum Vog.

Leguminosae (Indeterminada 1)

Mimosaceae (Indeterminada 1)

\section{Magnoliaceae}

Talauma ovata St.-Hil.

\section{Malpighiaceae}

Byrsonima cf. laxiflora Griseb.

\section{Melastomataceae}

Miconia chamissois Naud.

M. chartacea Triana

M. cuspidata Naud.
$\mathrm{O}$

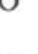

O

O 4

S 16

O 0

S 11

U 20

O 5

O 5

O 3

O 0

O 2

$\mathrm{Ce} \quad 9$

Ms 2

O 0

O 0

$\mathrm{O} \quad 0$

$\mathrm{S}$

O

$\mathrm{S}$

Cl

$\mathrm{Ce}$

$\mathrm{O}$

$\mathrm{Cl}$

$\mathrm{Cl}$

$\mathrm{O}$

O

O

O

O

O

O

$\mathrm{O}$

O

$\mathrm{C}$

$\mathrm{O}$

$\mathrm{Cl}$

$\mathrm{U}$

$\mathrm{O}$

o

$\begin{array}{lll}\text { U } & 21 & 24\end{array}$

$\begin{array}{lll}\text { O } & 12 \quad 9\end{array}$

0,00
2,56
5,13
20,51
0,00
14,10
25,64
6,41
6,41
3,85

0,63

0,000

0,007

132

$$
\begin{array}{ll}
0,00 & 0,047
\end{array}
$$

0,000

$0,63 \quad 0,034$

$24,68 \quad 0,976$

$1,27 \quad 0,000$

$25,32 \quad 0,113$

$\begin{array}{ll}8,23 & 0,756\end{array}$

$\begin{array}{ll}2,53 & 0,025\end{array}$

$3,80 \quad 0,155$

$0,00 \quad 0,015$

0,002

$2,226 \quad 14 \quad 4$

0,086 - 92

$\begin{array}{lll}0,302 & 41 & 13\end{array}$

$\begin{array}{lll}0,147 & 12 & 35\end{array}$

$\begin{array}{lll}0,011 & 74 & 89\end{array}$

$\begin{array}{lll}0,258 & 53 & 44\end{array}$

$0,000 \quad 96$

0,00

$4,43 \quad 0,000$

0.191

57

2,56

$\begin{array}{ll}3,17 & 0,242\end{array}$

$0,63 \quad 0,197$

$\begin{array}{lll}0,035 & 62 & 76\end{array}$

11,54

2,56

\begin{tabular}{l}
$9,49 \quad 0,056$ \\
\hline
\end{tabular}

$\begin{array}{lll}0,070 & 48 & 103\end{array}$

0,00

$2.53 \quad 0,000$

$\begin{array}{lll}0,798 & 106 & 17\end{array}$

0,00

$\begin{array}{ll}1,27 & 0,000\end{array}$

0,00

1,27

0,000

$0,154-69$

$0,041-108$

5,13

$\begin{array}{ll}27.85 & 0.034\end{array}$

$0,175-74$

0,00

$0,63 \quad 0,000$

0,409

77

0,012

0,00

$34,18 \quad 2,131$

$\begin{array}{ll}5,70 & 0,000\end{array}$

2,56

$\begin{array}{ll}0,00 & 0,020\end{array}$

2,56

$3,17 \quad 0,268$

3,85

$5,70 \quad 0,025$

0,00

$5,06 \quad 0,000$

2,56

36,0

1,27

0,008

0,00

1,90

0,000

2,56

5,70

0,028

$\begin{array}{ll}1,27 & 0,030\end{array}$

1,28

0,00

0,003

$\begin{array}{ll}2.53 & 0.055\end{array}$

$3,80 \quad 0,000$

$0,63 \quad 0,109$

1,945

0,083

0,000

0,458

0,09

0,10

$0,547 \quad 104$

0,102

$0,025-100$

$\begin{array}{lll}0,227 & 98 & 41\end{array}$

$\begin{array}{lll}0,023 & 112 & 114\end{array}$

$\begin{array}{lll}0,000 & 123 & -\end{array}$

$0,030 \quad 91 \quad 91$

0.00

2,56

3.85

17,95

$\begin{array}{ll}1,27 & 0,123\end{array}$

0.167 - 60

$\begin{array}{lll}0,016 & 81 & 124\end{array}$

$0,00 \quad 0,409$

$\begin{array}{lll}0.077 & 75 & 94\end{array}$

0,00

$1,27 \quad 0,000$

$0,000 \quad 32$ -

0,00

$5,06 \quad 0,000$

$0,023-106$

1,28

$12,66 \quad 0.020$

0,223

114

27

6,41

$0,63 \quad 0,036$

0,002

64

139

0,00

$1,27 \quad 0,000$

0,006

- 112

26,92

$15,19 \quad 0,167$

0,082

$23 \quad 37$

15,39

$\begin{array}{lll}0,079 & 33 & 49\end{array}$ 
Tabela 1. (continuação)

Família

$\mathrm{Hab}$

Espécie

$\frac{\mathrm{N}}{\mathrm{AC}} \mathrm{RF} \quad \frac{\mathrm{DENS}}{\mathrm{AC} \quad \mathrm{RF}} \frac{}{\mathrm{AC} \quad \mathrm{RF}} \frac{\mathrm{POS}}{\mathrm{AC} \quad \mathrm{RF}}$

Melastomataceae

Miconia dodecandra (Desv.) Cogn.

M. hirtella Cogn.

Miconia sp.

Mouriri glazioviana Cogn.

Tibouchina candolleana (DC.) Cogn.

Trembleya parviflora (D. Don.) Cogn.

Meliaceae

Guarea macrophylla Vahl. ssp. tuberculata

(Vell.) Pennington

Trichilia catigua Adr. Juss.

Monimiaceae

Macropeplus ligustrinus (Tul.) Perk.

Moraceae

Ficus insipida Willd.

Ficus sp. 1

Ficus sp. 2

Pseudolmedia laevigata Tréc.

Sorocea ilicifolia Miq.

Moraceae (Indeterminada 1)

Ce $19 \quad 0$

$\begin{array}{lll}\mathrm{Cl} & 5 & 15\end{array}$

O $0 \quad 1$

$\begin{array}{lll}\mathrm{O} & 3 & 4\end{array}$

$\begin{array}{lll}\mathrm{Cl} & 0 & 88\end{array}$

O 22

24,36

6,41

$0,00 \quad 0,162$

0,000

0,03

0,00

$9,49 \quad 0,030$

0,002

3,85

$0,63 \quad 0,000$

0,007

0,00

$2.53 \quad 0,016$

2,56

$55,70 \quad 0,000$

0,748

0,005

$1,27 \quad 0,041$

5,13

$\begin{array}{ll}0,00 & 0,029\end{array}$

0,000

8

$\begin{array}{lll}\mathrm{O} & 4 & 0 \\ \mathrm{O} & 0 & 5\end{array}$

0,00

$3,17 \quad 0,000$

0,014

1,28

$\begin{array}{ll}0,00 & 0,003\end{array}$

0,000

124

$\begin{array}{lll}\mathrm{O} & 8 & 1\end{array}$

10,26

$\begin{array}{ll}0,63 & 0,049\end{array}$

0,002

$57 \quad 144$

$\begin{array}{llll}\mathrm{U} & 6 & 0 & 7,69\end{array}$

$0,00 \quad 0,337$

$\begin{array}{lrrr}\mathrm{Cl} & 1 & 3 & 1,28 \\ \mathrm{U} & 48 & 2 & 61.54\end{array}$

$1,90 \quad 0,005$

0,000

3

$1,27 \quad 0,608$

$\begin{array}{lll}0,039 & 118 \quad 93\end{array}$

0,00

$3,17 \quad 0,000$

0,00

$0,630,000$

$0,023 \quad 7 \quad 105$

O $0 \quad 5$

O $0 \quad 1$

Ce 16

O 0

20,51

$\begin{array}{ll}1,90 & 0,365\end{array}$

0,00

Virola urbaniana Warb.

\section{Myrsinaceae}

Rapanea guianensis Aubl.

Myrsinaceae (Indeterminada 1)

Myrsinaceae (Indeterminada 2)

O $\quad 0 \quad 2$

0,00

0,00

1,28

O 1

Myrtaceae

Blepharocalyx salicifolius (H.B. \& K.) Berg

Calyptranthes clusiaefolia (Miq.) Berg

Campomanesia velutina (Camb.) Berg

Eugenia florida DC.

Gomidesia lindeniana Berg

Marlierea bipennis (Berg) McVaugh

Myrcia castrensis (Berg) Legr.

M. laroutteana Camb.

M. rostrata $\mathrm{DC}$.

M. tomentosa (Aubl.) DC.

Psidium rufum Mart. ex DC.

Siphoneugenia densiflora Berg

$\begin{array}{lrr}\mathrm{O} & 1 & 0 \\ \mathrm{O} & 2 & 2 \\ \mathrm{O} & 0 & 1 \\ \mathrm{O} & 0 & 1 \\ \mathrm{O} & 4 & 3 \\ \mathrm{O} & 2 & 1 \\ \mathrm{O} & 13 & 0 \\ \mathrm{O} & 0 & 4 \\ \mathrm{Ce} & 14 & 20 \\ \mathrm{Ms} & 3 & 27 \\ \mathrm{O} & 0 & 1 \\ \mathrm{O} & 2 & 2\end{array}$

1,28

2,56

0,00

0,00

5,13

2,56

16,67

0,00

17,95

3,85

0,00

2,56

$1,27 \quad 0,000$

0,013

- 81

$0,006-133$

Nyctaginaceae

Guapira graciliflora (Mart. ex Schimidt) Lund Nyctaginaceae (Indeterminada 1)

$\begin{array}{lll}\mathrm{O} & 0 & 2 \\ \mathrm{Ce} & 3 & 1\end{array}$

0,00

$\begin{array}{ll}1,27 & 0,000\end{array}$

$0,63 \quad 0,000$

$0,00 \quad 0,003$

2

0,007

$0,00 \quad 0,003$

$1,27 \quad 0,018$

$0.630,000$

$0,008-110$

$0,630,000$

$\begin{array}{ll}1,90 & 0,070\end{array}$

$\begin{array}{ll}0,63 & 0,009\end{array}$

$0,00 \quad 0,111$

$2,53 \quad 0,000$

$12,66 \quad 0,100$

$17,09 \quad 0,116$

$0,630,000$

$1,27 \quad 0,061$

$0,002-147$

Ochnaceae Ouratea castaneaefolia (DC.) Engl.

\section{Olacaceae}

Heisteria sp.

S $\quad 4 \quad 30$

5,1

7,69

$1,27 \quad 0,000$

$0,63 \quad 0,041$

0,066 - 97

3,85

$18,99 \quad 0,031$

$0,155 \quad 68$

20

Ce 60

0,00

0,6

$0,00 \quad 0,084$

$0,000 \quad 69=$

Chionanthus sp.
O 0 
Tabela 1. (continuação)

Familia Espécie
$\mathrm{Hab}$

$\frac{\mathrm{N}}{\mathrm{AC}} \mathrm{RF} \quad \frac{\mathrm{DENS}}{\mathrm{AC} \quad \mathrm{RF}} \frac{\mathrm{DOM}}{\mathrm{AC} \quad \mathrm{RF}} \frac{\mathrm{POS}}{\mathrm{AC} \quad \mathrm{RF}}$

\section{Palmae}

Euterpe edulis Mart.

Mauritia flexuosa L.f.

Syagrus romanzoffiana (Cham.) Glassman S. flexuosa L.f.

Proteaceae

Euplassa inaequalis (Pohl.) Engl.

Roupala montana Aubl.

\section{Rosaceae}

Prunus chamissoana Koehne Prunus sp.

Rubiaceae

Alibertia sessilis (Vell) K. Schum.

Amaioua guianensis Aubl.

Coutarea hexandra (Jacq.) K. Schum.

Faramea cyanea Müll. Arg.

Faramea sp.

Ferdinandusa speciosa Pohl

Guettarda viburnoides Cham. \& Schlecht.

Ixora warmingii Müll. Arg.

Rustia formosa (Cham. \& Schlecht.)

Klotzsch

Rubiaceae (Indeterminada 1)

\section{Rutaceae}

Metrodorea stipularis Mart.

Zanthoxylum rhoifolium Lam.

\section{Sapindaceae}

Cupania vernalis $\mathrm{Camb}$.

Matayba guianensis Aubl.

\section{Sapotaceae}

Micropholis venulosa (Mart. \& Eichl.)

Pierre

Pouteria ramiflora (Mart.) Radlk.

P. torta (Mart.) Radlk.

\section{Solanaceae}

Cestrum megalophyllum Dunal

\section{Sterculiaceae}

Guazuma ulmifolia Lam.

\section{Styracaceae}

Styrax camporum Pohl

\section{Symplocaceae}

Symplocos mosenii Brand.

$S$. rhamnifolia A. DC.

\section{Theaceae}

Laplacea fruticosa (Schrader) Kobuski

\section{Tiliaceae}

Apeiba tibourbou Aubl.

Luehea cf. grandiflora Mart. \& Zucc.

\section{Verbenaceae}

$\begin{array}{lrrrrrrrr}\mathrm{O} & 10 & 6 & 12,82 & 3,80 & 0,140 & 0,060 & 52 & 79 \\ \mathrm{O} & 2 & 0 & 2,56 & 0,00 & 0,182 & 0,000 & 70 & - \\ \mathrm{O} & 1 & 2 & 1,28 & 1,27 & 0,006 & 0,035 & 117 & 101 \\ \mathrm{O} & 2 & 0 & 2,56 & 0,00 & 0,009 & 0,000 & 111 & - \\ \mathrm{U} & 9 & 4 & 11,54 & 2,53 & 0,165 & 0,033 & 45 & 85 \\ \mathrm{Ms} & 3 & 9 & 3,85 & 5,70 & 0,021 & 0,119 & 83 & 61 \\ & & & & & & & & \\ \mathrm{O} & 4 & 2 & 5,13 & 1,27 & 0,047 & 0,005 & 66 & 121 \\ \mathrm{O} & 1 & 0 & 1,28 & 0,00 & 0,003 & 0,000 & 126 & - \\ & & & & & & & & \\ \mathrm{S} & 11 & 67 & 14,10 & 42,41 & 0,104 & 0,362 & 42 & 9 \\ \mathrm{U} & 33 & 21 & 42,31 & 13,29 & 0,569 & 0,124 & 10 & 24 \\ \mathrm{Ms} & 0 & 18 & 0,00 & 11,39 & 0,000 & 0,118 & - & 40 \\ \mathrm{~S} & 56 & 75 & 71,80 & 47,47 & 0,593 & 0,374 & 4 & 6 \\ \mathrm{O} & 0 & 2 & 0,00 & 1,27 & 0,000 & 0,003 & - & 113 \\ \mathrm{U} & 5 & 0 & 6,41 & 0,00 & 0,113 & 0,000 & 59 & - \\ \mathrm{Ms} & 1 & 15 & 1,28 & 9,49 & 0,062 & 0,062 & 107 & 39 \\ \mathrm{O} & 3 & 19 & 3,85 & 12,03 & 0,019 & 0,167 & 84 & 25 \\ & & & & & & & & \\ \mathrm{O} & 0 & 1 & 0,00 & 0,63 & 0,000 & 0,004 & - & 134 \\ \mathrm{O} & 0 & 1 & 0,00 & 0,63 & 0,000 & 0,012 & - & 126 \\ \mathrm{~S} & 14 & 185 & 17,95 & 117,1 & 0,498 & 1,807 & 25 & 1 \\ \mathrm{O} & 2 & 5 & 2,56 & 3,17 & 0,013 & 0,103 & 109 & 70 \\ \mathrm{Ms} & 3 & 10 & 3,85 & 6,33 & 0,034 & 0,064 & 78 & 64 \\ \mathrm{Ce} & 23 & 31 & 29,49 & 19,62 & 0,317 & 0,231 & 16 & 19\end{array}$

\begin{tabular}{|c|c|c|c|c|c|c|c|c|}
\hline $\mathrm{U}$ & 7 & 11 & 8,97 & 6,96 & 0,126 & 0,228 & 50 & 32 \\
\hline $\mathrm{Ce}$ & 2 & 13 & 2,56 & 8,23 & 0,006 & 0,087 & 105 & 53 \\
\hline S & 5 & 20 & 6,41 & 12,66 & 0,718 & 0,522 & 29 & 18 \\
\hline $\mathrm{O}$ & 0 & 1 & 0,00 & 0,63 & 0,000 & 0,001 & - & 150 \\
\hline $\mathrm{O}$ & 0 & 5 & 0,00 & 3,17 & 0,000 & 0,085 & - & 78 \\
\hline $\mathrm{U}$ & 27 & 18 & 34,62 & 11,39 & 0,329 & 0,097 & 18 & 29 \\
\hline $\mathrm{U}$ & 11 & 1 & 14,10 & 0,63 & 0,485 & 0,022 & 24 & 119 \\
\hline $\mathrm{O}$ & 1 & 0 & 1,28 & 0,00 & 0,003 & 0,000 & 121 & - \\
\hline $\mathrm{O}$ & 12 & 0 & 15,39 & 0,00 & 0,140 & 0,000 & 54 & - \\
\hline $\mathrm{O}$ & 0 & 2 & 0,00 & 1,27 & 0,000 & 0,076 & - & 95 \\
\hline $\mathrm{O}$ & 2 & 0 & 2,56 & 0,00 & 0,035 & 0,000 & 97 & - \\
\hline $\mathrm{O}$ & 0 & 7 & 0,00 & 4,43 & 0,000 & 0,113 & - & 66 \\
\hline
\end{tabular}


Tabela 1. (continuação)

\begin{tabular}{|c|c|c|c|c|c|c|c|c|c|}
\hline \multirow{2}{*}{$\begin{array}{l}\text { Família } \\
\text { Espécie }\end{array}$} & \multirow[t]{2}{*}{ Hab } & \multicolumn{2}{|c|}{$\mathrm{N}$} & \multicolumn{2}{|c|}{ DENS } & \multicolumn{2}{|c|}{ DOM } & \multicolumn{2}{|c|}{ POS } \\
\hline & & $\overline{\mathrm{AC}}$ & $\mathrm{RF}$ & $\overline{\mathrm{AC}}$ & RF & $\overline{\mathrm{AC}}$ & RF & $\overline{\mathrm{AC}}$ & RF \\
\hline \multicolumn{10}{|l|}{ Verbenaceae } \\
\hline Vitex polygama Cham. & $\mathrm{Ce}$ & 10 & 2 & 12,82 & 1,27 & 0,230 & 0,015 & 47 & 116 \\
\hline \multicolumn{10}{|l|}{ Vochysiaceae } \\
\hline Callisthene major Mart. & $\mathrm{Ce}$ & 30 & 11 & 38,46 & 6,96 & 0,668 & 0,099 & 11 & 30 \\
\hline Qualea dichotoma (Mart.) Warm. & Ms & 1 & 5 & 1,28 & 3,17 & 0,028 & 0,325 & 113 & 42 \\
\hline Q. grandiflora Mart. & $\mathrm{O}$ & 1 & 0 & 1,28 & 0,00 & 0,004 & 0,000 & 119 & - \\
\hline Q. multiflora Mart. & Ms & 2 & 12 & 2,56 & 7,60 & 0,328 & 0,100 & 56 & 43 \\
\hline Vochysia tucanorum Mart. & $\mathrm{Ce}$ & 3 & 3 & 3,85 & 1,90 & 0,031 & 0,014 & 80 & 102 \\
\hline TOTAIS & & 1228 & 1831 & 1574 & 1159 & 30 & 26 & - & - \\
\hline
\end{tabular}

langsdorffii, Tapirira guianensis, Protium heptaphyllum, Faramea cyanea, Licania apetala, Protium almecega, Pseudolmedia laevigata, Richeria grandis, Terminalia glabrescens e Amaioua guianensis. Enquanto nas parcelas do Açudinho Pseudolmedia laevigata foi uma espécie importante, no Riacho Fundo foram amostrados apenas dois indivíduos (Tab. 1). Richeria grandis, outra espécie importante na mata do Açudinho, nem mesmo ocorreu no Riacho Fundo (Tab. 1). Por outro lado, Tibouchina candolleana, importante no Riacho Fundo, não ocorreu nas parcelas do Açudinho (Tab. 1).

O Índice de Similaridade de Sørensen (IS) entre as matas do Açudinho e Riacho Fundo foi de $69 \%$, o que demonstra alta similaridade florística entre essas comunidades arbóreas. Portanto, apesar da grande variação na importância das espécies entre estas matas (Tab. 1), elas compartilham várias espécies em comum. Estes resultados indicam diferenças estruturais, embora seja pouca a variação florística entre as matas.

Classificação das comunidades arbóreas O dendrograma apresentado na Fig. 2, tendo como variável a densidade das espécies, separou na primeira divisão as parcelas da grande clareira do Riacho Fundo, grupo Q/R/S (parcelas da clareira na linha L2), das demais. O gru- po $\mathrm{Q} / \mathrm{R} / \mathrm{S}$ comporta tanto parcelas em solos bem drenados (parcelas 41 e 48), quanto parcelas em solos mal drenados (parcelas 38, 39, 40, 42, 43, $44,45,46,47)$. As parcelas do grupo $\mathrm{A} / \mathrm{B} / \mathrm{C} / \mathrm{D} /$ $\mathrm{E} / \mathrm{F} / \mathrm{G} / \mathrm{H} / \mathrm{I} / \mathrm{J} / \mathrm{K} / \mathrm{L} / \mathrm{M} / \mathrm{N} / \mathrm{O} / \mathrm{P}$, preferencialmente, encontram-se em condição de dossel fechado. Este grupo foi separado pela segunda divisão em parcelas com solos bem drenados (grupo G/ $\mathrm{H} / \mathrm{I} / \mathrm{J} / \mathrm{K} / \mathrm{L} / \mathrm{M} / \mathrm{N} / \mathrm{O} / \mathrm{P}$ ), e parcelas com drenagem deficiente (grupo $\mathrm{A} / \mathrm{B} / \mathrm{C} / \mathrm{D} / \mathrm{E} / \mathrm{F}$ ) (Fig. 2). As divisões do dendrograma (Fig. 2) apresentam todos os autovalores iguais ou acima de 0,3 , indicando que todas foram robustas (Hill et al. 1975). Ou seja, há baixa similaridade entre cada um dos grupos de parcelas formados pela classificação.

As parcelas no grupo da clareira têm como espécie indicadora, na primeira divisão, Tibouchina candolleana. Esta espécie ocorreu exclusivamente em ambientes com boa disponibilidade de luz e água. As espécies Inga sp., Cecropia cf. pachystachia, Dalbergia densiflora, Miconia hirtella, Hedyosmum brasiliense e Ficus sp. 2 ocorreram em maiores densidades nas parcelas do grupo $\mathrm{Q} / \mathrm{R} / \mathrm{S}$ (grande clareira do Riacho Fundo - Tab. 1). Walter \& Ribeiro (1997) classificaram Tibouchina candolleana e Hedyosmum brasiliense como exclusivas e Miconia hirtella como preferencial de ambientes inundáveis em matas de galeria. 


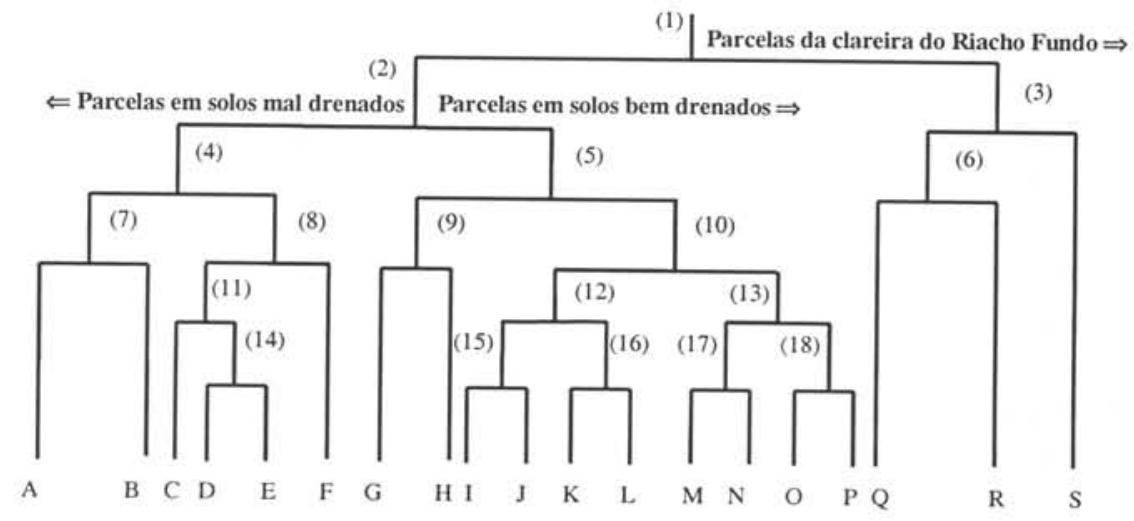

Figura 2 - Dendrograma das parcelas das matas de galeria dos córregos Riacho Fundo e Açudinho, gerado pela classificação dos dados de densidade das espécies nas parcelas, pelo método TWINSPAN. Divisões indicadas por números e "grupos" de parcelas indicados por letras. Autovalores ("eigenvalue") das divisões: (1) - 0,550; (2) - 0,550; (3) - 0,500; (4) $-0,474 ;(\mathbf{5})-0,373 ;(6)-0,452 ;(7)-0,471 ;(8)-0,471 ;(\mathbf{9})-0,541 ;(\mathbf{1 0})-0,375 ;(\mathbf{1 1})-0,484 ;(\mathbf{1 2})-0,302 ;(\mathbf{1 3})-$ 0,$461 ;(\mathbf{1 4})-0,491 ;(\mathbf{1 5})-0,582 ;(\mathbf{1 6})-0,295 ;$ (17) - 0,507; (18) - 0,496. Parcelas dos grupos: A - $94,98,102 ; \mathbf{B}-89$, $103 ; \mathbf{C}-104,105 ; \mathbf{D}-82,84 ; \mathbf{E}-83,90,95,99 ; \mathbf{F}-49,68,70,71 ; \mathbf{G}-97,101 ; \mathbf{H}-80,86,87,88 ; \mathbf{I}-81,92,93 ; \mathbf{J}-26$, $27,28,29,30,54,112 ; \mathbf{K}-6,15,22,23,25,35,50,55,56,57,58,60,61,62,63,65,67,72,113,115 ; \mathbf{L}-3,5,8,9$, $11,12,14,16,18,19,20,21,34,36,52,53,59,64,66,79,107,109,110,116 ; \mathbf{M}-17,31,32,33 ; \mathbf{N}-117,118 ; \mathbf{O}-73$, $74,75,76,77,78 ; \mathbf{P}-13 ; \mathbf{Q}-46,47,48 ; \mathbf{R}-39,40,41,45 ; \mathbf{S}-38,42,43,44$. Dezessete parcelas do levantamento não foram consideradas pois foram mal classificadas pelo TWINSPAN (parcelas $\mathrm{n}^{\circ}: 1,2,4,7,10,24,37,51,69,85,91,96$, $100,106,108,111,114)$.

As parcelas localizadas em solos mal drenados, agrupadas pela segunda divisão do dendrograma (Fig. 2), comportaram 24 espécies (Tab. 1) que ocorreram com maiores densidades nestes ambientes. Todas foram anteriormente classificadas por diversos estudos de acordo com o ambiente preferencial em que ocorrem (p.ex., Felfili 1995; 1998; Silva Jr. 1995; Walter 1995; Walter \& Ribeiro 1997), utilizando-se tanto análises multivariadas como observações de campo, embora Maprounea guianensis, Schefflera morototoni, Symplocos mosenii e Xylopia sericea não tenham sido indicadas como preferenciais de solos mal drenados, como agora o foram. Vale ressaltar, no entanto, que estas quatro espécies também ocorreram em menores densidades sobre solos bem drenados nas matas do presente estudo.

As espécies que ocorrem com maiores densidades no grupo das parcelas em solos bem drenados (G/H/I/J/K/L/M/N/O/P - Fig. 2) estão indicadas na Tab. 1. Este grupo foi formado pela maioria das parcelas amostradas nas duas matas, combinando parcelas do trecho Final do Açudinho e das três linhas do Riacho Fundo. A partir do grupo de parcelas em solos bem drenados foram separados outros dois, grupos $\mathrm{G} / \mathrm{H}$ e I/J/K/L/M/N/O/P, os quais apresentam parcelas com características particulares, discutidas a seguir.

O grupo G/H (ecótono mata/cerrado - Tab. 1), composto por parcelas em solos bem drenados, localizadas nas bordas da mata do Açudinho (Cabeceira e Porção Central) e na interface com áreas de cerrado sentido restrito ou campo (Fig. 1), foi separado pela divisão número cinco (Fig. 2). As espécies que ocorreram neste grupo, com maiores densidades, estão listadas na Tab. 1. Dentre estas estão Dalbergia miscolobium, Sclerolobium paniculatum, Callisthene major e Lamanonia ternata, espécies classificadas por Felfili (1995) como indicadoras de áreas de bor- 
da entre mata de galeria e fitofisionomias de cerrado (sentido amplo). Dessa forma, as parcelas do grupo $\mathrm{G} / \mathrm{H}$ foram bastante influenciadas pelas fitofisionomias adjacentes.

As parcelas que formaram o grupo $\mathrm{M} / \mathrm{N} / \mathrm{O} /$ $\mathrm{P}$ (com elementos de mata seca - Tab. 1) estão localizadas no Trecho Final do Açudinho e nas três linhas do Riacho Fundo (Fig. 1 e 2). As espécies com maiores densidades nas parcelas desse grupo M/N/O/P estão indicadas na Tab. 1 . Estas espécies tanto ocorrem em matas de galeria como em matas secas, dentre as quais encontram-se duas espécies do gênero Anadenanthera, típico de matas secas (Ratter et al. 1978; Ribeiro \& Walter 1998). Além daquelas espécies, também ocorrem neste grupo, com menores densidades, outras plantas características de matas secas, entre as quais: Apeiba tibourbou, Astronium fraxinifolium, Cariniana estrellensis e Eriotheca gracilipes.

De acordo com Ratter et al. (1978), espécies como Apeiba tibourbou e Astronium fraxinifolium seriam calcífilas. Assim, a presença dessas espécies nas parcelas do grupo M/N/O/P (Fig. 2) pode estar indicando solos mesotróficos, com teores de cálcio e magnésio possivelmente mais elevados. Portanto, são necessárias análises edáficas detalhadas para determinar os possíveis fatores abióticos condicionantes do grupo $\mathrm{M} / \mathrm{N} / \mathrm{O} / \mathrm{P}$.

Além da primeira e da segunda divisão do dendrograma (Fig. 2), quase todas as demais (exceto a $8^{\mathrm{a}} \mathrm{e} 17^{\mathrm{a}}$ divisões) agruparam parcelas desconsiderando a distância entre elas. Tais divisões combinaram parcelas das duas matas estudadas, como foi o caso do grupo $\mathrm{I} / \mathrm{J} / \mathrm{K} / \mathrm{L}$, de parcelas não inundáveis. Desse modo, a classificação indicou que as condições ambientais têm maior relevância na distribuição das espécies pela vegetação do que a distância entre os locais amostrados.

Pela discussão anterior, a classificação conjunta das comunidades arbóreas, a partir dos dados de densidade das espécies, indicou que as características ambientais foram os principais determinantes na distribuição das espécies. Dessa maneira, existem três grupos principais de espécies preferenciais de determinados ambientes, indicados por parcelas em locais bem drenados (grupo $\mathrm{G} / \mathrm{H} / \mathrm{I} / \mathrm{J} / \mathrm{K} / \mathrm{L} / \mathrm{M} / \mathrm{N} / \mathrm{O} / \mathrm{P}$ - Fig. 2), parcelas em solos mal drenados (grupo $\mathrm{A} / \mathrm{B} / \mathrm{C} / \mathrm{D} / \mathrm{E} / \mathrm{F}$ - Fig. 2) e parcelas em clareira (grupo $Q / R / S$ Fig. 2). Tais associações de espécies estão relacionadas às condições de drenagem do solo e ao estádio sucessional da vegetação. Além disso, a influência das fitofisionomias adjacentes e possíveis variações na fertilidade dos solos podem estar interferindo na distribuição espacial da comunidade arbórea. Estas associações poderiam explicar as diferenças na abundância das espécies arbóreas encontradas entre as matas do Açudinho e do Riacho Fundo, pois em cada uma destas matas existem condições abióticas distintas.

A mesma relação entre as comunidades arbóreas destas matas, e os fatores abióticos, estádio sucessional e disponibilidade de água, foi mantida quando a classificação foi realizada com dados de presença ou ausência (Fig. 3) e de área basal (Fig. 4). Nesta última análise, parcelas em solos mal drenados da clareira do Riacho Fundo (41 e 48) e parcelas próximas a estas $(38,39,44$ e 45$)$, também em solos com drenagem deficiente, foram agrupadas no grupo $\mathrm{M} /$ N/O (Fig. 4). Em consequiência, quando se considera a área basal como o parâmetro de análise, a drenagem do solo torna-se fator ainda mais importante para explicar a distribuição das espécies arbóreas, do que quando se considera a presença ou ausência, ou a densidade das espécies.

Mesmo que os três dendrogramas construídos, com tipos de dados distintos (densidade, presença e ausência, e área basal), tenham indicado padrões gerais semelhantes (Fig. 2, 3 e 4), aquele com dados de densidade apresentou mais grupos de parcelas, ou sub-unidades das comunidades, que podem ser explicados por variações das condições bióticas e abióticas. Além disso, o dendrograma com da- 


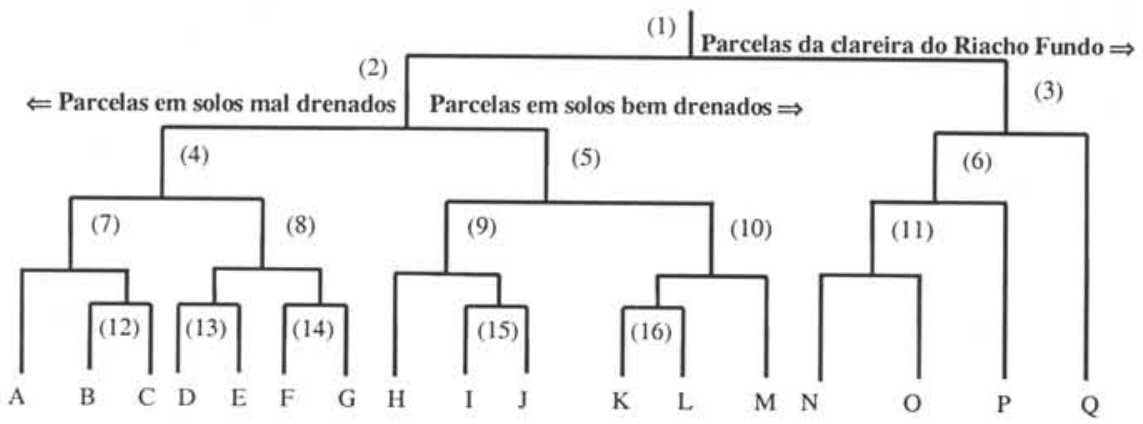

Figura 3 - Dendrograma das parcelas das matas de galeria dos córregos Riacho Fundo e Açudinho, gerado pela classificação dos dados de presença ou ausência das espécies nas parcelas, pelo método TWINSPAN. Divisões indicadas por números e "grupos" de parcelas indicados por letras. Autovalores ("eigenvalue") das divisões: (1) - 0,528 ; (2) - 0,475; (3) $-0,479 ;(\mathbf{4})-0,430 ;(\mathbf{5})-0,357 ;(\mathbf{6})-0,480 ;(\mathbf{7})-0,420 ;(\mathbf{8})-0,400 ;(\mathbf{9})-0,265 ;(\mathbf{1 0})-0,364 ;(\mathbf{1 1})-0,471 ;(\mathbf{1 2})-0,498 ;$ (13) - 0,633; (14) - 0,386; (15) - 0,251; (16) - 0,362. Parcelas dos grupos: A - 90, 99, 103; B - 89, 94, 98, 102; C - 104; D - $71 ; \mathbf{E}-26,28,30,70 ; \mathbf{F}-82,83,84,88,91,96,97,100,101,105 ; \mathbf{G}-85,92,93 ; \mathbf{H}-72,86 ; \mathbf{I}-1,4,5,8,9,11,14$, $21,22,58,59,110,111 ; \mathbf{J}-2,6,10,15,16,24,25,27,36,50,53,54,55,57,60,61,62,63,64,65,66,114,115,116$; $\mathbf{K}-3,13,20,73,74,75,76,77,78,106,108 ; \mathbf{L}-31,32,33,51,117,118 ; \mathbf{M}-80 ; \mathbf{N}-39,40,45 ; \mathbf{O}-38,41,44 ; \mathbf{P}-42$, 43; Q - 46, 47, 48. Parcelas mal classificadas: 7, 12, 17, 18, 19, 23, 29, 34, 35, 37, 49, 52, 56, 67, 68, 69, 79, 81, 87, 95, $107,109,112,113$.

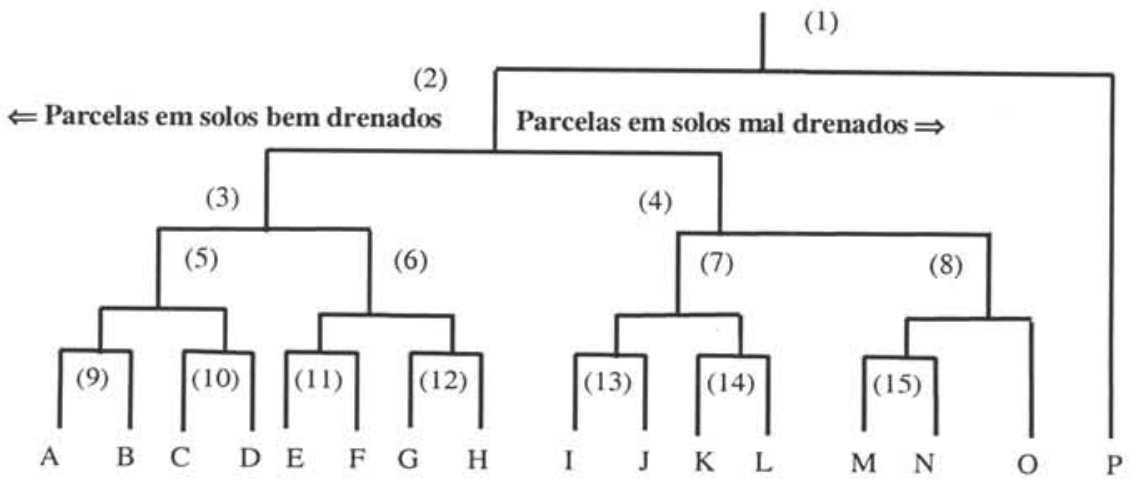

Figura 4 - Dendrograma das parcelas das matas de galeria dos córregos Riacho Fundo e Açudinho, gerado pela classificação dos dados de área basal das espécies nas parcelas, pelo método TWINSPAN. Divisões indicadas por números e "grupos" de parcelas indicados por letras. Autovalores ("eigenvalue") das divisões: (1) - 0,484; (2) - 0,471; (3) - 0,338; (4) $-0,681 ;(\mathbf{5})-0,376 ;(6)-0,330 ;(\mathbf{7})-0,430 ;(8)-0,536 ;(\mathbf{9})-0,547 ;(\mathbf{1 0})-0,420 ;(\mathbf{1 1})-0,269 ;(\mathbf{1 2})-0,520 ;(\mathbf{1 3})$ 0,$412 ;(\mathbf{1 4})-0,484 ;$ (15) - 0,524. Parcelas dos grupos: A - 80; B - 37, 73, 74, 75, 76, 77, 78; C - 31, 32, 33, 51, 107, 118; D - $3,13,17,18,20,34,106,108,117$; E - 2, 4, 6, 7, 8, 10, 11, 12, 14, 15, 16, 21, 22, 24, 26, 30, 36, 50, 53, 54, 55, 56, $57,58,59,60,61,62,63,64,65,66,110,111,114,115,116 ; \mathbf{F}-72 ; \mathbf{G}-27,28,81,85,86,88,92,93 ; \mathbf{H}-1 ; \mathbf{I}-70,71$; $\mathbf{J}-82,83,84,90,91,96,97,100,101,104,105 \mathbf{K}-99,103 ; \mathbf{L}-89,94,98,102 ; \mathbf{M}-41,44 ; \mathbf{N}-38,39,45 ; \mathbf{O}-48 ; \mathbf{P}$ - 42, 43, 47. Parcelas mal classificadas: 5, 9, 19, 23, 25, 29, 35, 40, 46, 49, 52, 67 ,68, 69, 79, 87, 95 ,109, $112,113$. 
dos de densidade foi o que incluiu menos parcelas mal classificadas, comparado aos demais (densidade - 17 parcelas mal classificadas - Fig. 2.; presença e ausência - 24 parcelas mal classificadas - Fig. 3; área basal - 20 parcelas mal classificadas - Fig. 4). Portanto, as comunidades das matas do Açudinho e Riacho Fundo foram melhor classificadas quando dados de densidade foram utilizados nas análises.

Caracterização dos grupos de parcelas - A comparação dos dados médios de densidade, área basal e altura, além das medianas de DAP dos três principais grupos de parcelas identificados pela classificação (dados de densidade Fig. 2), indicou distinção evidente na estrutura de tamanho dos indivíduos destes grupos, ou sub-unidades das comunidades arbóreas (Tab. 2). Os valores médios de área basal, a altura e a mediana de DAP foram significativamente menores no grupo de parcelas em clareira. A área basal e a altura média não variaram entre os grupos de parcelas em solos inundáveis e nãoinundáveis (Tab. 2). O grupo de parcelas nãoinundáveis apresentou a maior mediana de DAP (Tab. 2). Já a densidade das parcelas em solos não-inundáveis e em clareira foi semelhante e significativamente menor que a densidade das parcelas em solos inundáveis (Tab. 2). Deste modo, o grupo de parcelas em locais inundáveis apresenta árvores mais finas e adensadas que as do grupo em solos não-inundáveis (bem drenados). Esta indicação encontra respaldo em outros estudos realizados neste tipo de ambiente de matas de galeria, como por exemplo o de Walter (1995). Portanto, a drenagem do solo e o estádio sucessional demonstraram forte influência sobre a estrutura das comunidades arbóreas das matas do Açudinho e Riacho Fundo.

A Tab. 2 apresenta ainda o número de indivíduos, espécies e famílias encontrados em cada um dos três grupos. Das espécies amostradas no grupo de parcelas em solos bem drenados, 27 $(18,2 \%)$ delas pertencem à família Leguminosae. No grupo das parcelas em clareira, a família Leguminosae também apresentou o maior número de espécies (sete espécies, ou 20\%). Mas, no grupo de parcelas em solos mal drenados, a família Myrtaceae foi a que apresentou o maior número de espécies (oito espécies, ou 9,5\%), enquanto Leguminosae comportou seis espécies $(7,1 \%)$. São duas espécies a menos que Myrtaceae e, ainda assim, com apenas 12 indivíduos ao todo. A redução no número de Leguminosae em matas com solos inundáveis já foi evidenciada em estudos anteriores. Ratter

Tabela 2. Valores médios de área basal, densidade e altura, com respectivos intervalos de confiança $(\propto=0,05)$; medianas de DAP; número de parcelas e indivíduos amostrados; riqueza e número de famílias obtidos para os grupos não-inundáveis $(\mathrm{G} / \mathrm{H} / \mathrm{I} / \mathrm{J} / \mathrm{K} / \mathrm{L} / \mathrm{M} / \mathrm{N} / \mathrm{O} / \mathrm{P})$, inundáveis $(\mathrm{A} / \mathrm{B} / \mathrm{C} / \mathrm{D} / \mathrm{E} / \mathrm{F})$ e clareira $(\mathrm{Q} / \mathrm{R} / \mathrm{S})$, obtidos pela classificação com dados de densidade.

\begin{tabular}{lccc}
\hline & \multicolumn{3}{c}{ Grupos de parcelas } \\
\cline { 2 - 4 } Parâmetros & não-inundáveis & inundáveis & clareira \\
\hline Área basal (m²/ha) & $34,4( \pm 4,2)^{\mathrm{A}}$ & $33,3( \pm 5)^{\mathrm{A}}$ & $11,8( \pm 5)^{\mathrm{B}}$ \\
Densidade (Indivíduos/ha) & $1333( \pm 92,2)^{\mathrm{A}}$ & $2094( \pm 371)^{\mathrm{B}}$ & $1105( \pm 357)^{\mathrm{A}}$ \\
Altura (m) & $12,3( \pm 0,6)^{\mathrm{A}}$ & $12( \pm 1)^{\mathrm{A}}$ & $7,7( \pm 1,3)^{\mathrm{B}}$ \\
DAP (cm) & $10,5(173,3)^{*}$ & $9,3(53,7)^{*}$ & $8,1(40,8)$ \\
Parcelas & 73 & 17 & 11 \\
Indivíduos & 1949 & 712 & 243 \\
Riqueza & 148 & 84 & 35 \\
Famílias & 54 & 40 & 23 \\
\end{tabular}

Valores em cada coluna marcados por letras distintas, indicam diferença significativa (Teste Kruskal-Wallis, $\mathrm{P}<0,05$ ).

* Números entre parênteses indicam os valores máximos de DAP; valores mínimos $5 \mathrm{~cm}$. 
et al. (1973), por exemplo, encontraram apenas uma espécie de Leguminosae na mata de galeria que estudaram em Mato Grosso. Walter (1995) e Walter \& Ribeiro (1997) destacaram a ausência de leguminosas arbóreas em ambientes inundáveis de matas de galeria, característica que os torna distintos dos demais tipos de vegetação tropical.

Os resultados deste trabalho mostraram que trechos das matas do Açudinho e Riacho Fundo, sob condições abióticas semelhantes, foram mais similares florística e estruturalmente do que trechos próximos dentro de cada uma destas matas, sob condições abióticas diferentes. O principal fator determinante das comunidades arbóreas foi a drenagem do solo. A estas seguiram-se as fitofisionomias adjacentes e o histórico de perturbação. Assim, as variações na florística e na estrutura das matas do Açudinho e do Riacho Fundo foram descontínuas, acompanhando variações ambientais e os tipos de vegetação adjacentes, compondo mosaico de associações de espécies, distintas entre si.

A realização de análise direta de gradientes ainda se faz necessária para melhor compreensão dos fatores determinantes da distribuição espacial das espécies arbóreas, nas matas de galeria em questão. Não obstante, os padrões aqui encontrados devem ser aprofundados por meio de comparações com outros estudos, em matas de galeria localizadas em microbacias hidrográficas distintas. Somente desta maneira, poder-se-á traçar padrões mais amplos sobre a distribuição das espécies nesta fitofisionomia. A partir deste conhecimento, planos de conservação e recuperação de matas de galeria poderão ser traçados de maneira mais eficiente.

\section{Agradecimentos}

Agradecemos o auxílio de diversas pessoas nas atividades de campo, as quais forneceram as bases para este estudo. Dentre estas, João B. Pereira, Ricardo V. Nunes, Aécio A. Santos, Gustavo S. C. de Pinho e Ernestino S. G.
Guarino. À Carolyn Proença e Newton Rodrigues, pelo auxílio na identificação das coletas botânicas. Aos técnicos do herbário CEN, José G. Vieira, Rogério Vieira, Sônia Oliveira e Arnaldo Abiorana, pelo cuidadoso tratamento do material herborizado. À EMBRAPA Recursos Genéticos e Biotecnologia, pelo apoio financeiro e ao PIBIC/CNPq, pela bolsa de Iniciação Científica ao primeiro Autor.

\section{Referências bibliográficas}

Felfili, J. M. 1995. Diversity, structure, and dynamics of a gallery forest in Central Brazil. Vegetatio 177: $1-15$.

Felfili, J. M. 1998. Determinação de padrões de distribuição de espécies em uma mata de galeria no Brasil Central com a utilização de técnicas de análise multivariada. Boletim do Herbário Ezechias Paulo Heringer 2: 35-48.

Felfili, J. M; Filgueiras, T. S.; Haridasan, M.; Silva Jr., M. C.; Mendonça, R. C. \& Rezende, A. V. 1994. Projeto biogeografia do bioma cerrado: vegetação e solos. Cadernos de Geociências 12(4): 75-166.

Fowler, N. 1988. The effects of environmental heterogeneity in space and time on the regulation of population and communities. Pp. 249-269. In: A. J. Davy; M. J. Hutchings \& A. R. Watkinson (Eds.), Plant population ecology. Blackwell, Oxford.

Haridasan, M.; Silva Jr., M. C.; Felfili, J. M.; Rezende, A. V.\& Silva, P. E. N. 1997. Gradient of analysis of soil properties and phytosociological parameters some gallery forests on the Chapada dos Veadeiros in the region of the Central Brazil. Pp. 259-275. In: J. Imaña-Encinas \& C. Kleinn (Eds.), Proceedings of the international symposium on assessment and monitoring of forests in tropical dry regions with special reference to gallery forests, Brasília 1996. Universidade de Brasília, Brasília.

Hill, M. O. 1979. TWINSPAN - a FORTRAN program for arranging multivariate data in an ordered two-way table by classification of the individuals and attributes. Cornell University. Ithaca, New York.

Hill, M. O.; Bunce, R. G. H. \& Shaw, M. W. 1975. Indicator species analysis, a divisive polythetic method of classification, and its application to a survey of native pinewoods in Scotland. Journal of Ecology 63: 597-613.

Huston, M. 1979. A general hypothesis of species diversity. American Naturalist 113: 81-101. 
Kellman, M.; Tackaberry, R. \& Meave, J. 1996. The consequences of prolonged fragmentation: lessons from tropical gallery forests. Pp. 37-58. In: J. Schelhas \& R. Greenberg (Eds.), Forest patches in tropical landscapes. Island Press, Washington.

Kent, M. \& Coker, P. 1995. Vegetation description and analysis: a pratical approach. Belhaven Press, London.

Margurran, A. E. 1988. Ecological diversity and its measurements. Croom Helm, London.

Oliveira-Filho, A.T. 1989. Composição florística e estrutura comunitária da floresta de galeria do córrego da Paciência, Cuiabá, MT. Acta Botanica Brasilica 3(1): 91-112.

Oliveira-Filho, A. T.; Vilela, E. A.; Carvalho, D. A. \& Gavilanes, M.L. 1994. Effects of soil and topography on the distribution of tree species in a tropical riverine forest in a South-eastern Brazil. Journal of Tropical Ecology 10: 483-508.

Oliveira-Filho, A.T. \& Ratter, J. A. 1995. A study of the origin of Central Brazilian forests by the analysis of plant distribuition patterns. Edinburgh Journal of Botany 52(2): 1-54.

Pinto, M. N. 1994. Caracterização geomorfológica. Pp. 285-320. In: M. N. Pinto (Ed.), Cerrado: caracterização, ocupação e perspectivas. Universidade de Brasília/SEMATEC, Brasília.

Ratter, J. A.; Richards, P. W.; Argent, G. \& Gifford, D. R. 1973. Observations on vegetation of Northeastern Mato Grosso. Philosophical Transactions: Biological Sciences 226(880): 449-492.

Ratter, J. A.; Askew, G. P.; Montgomery, R. F. \& Gifford, D. R. 1978. Observations on forests of some mesotrophic soils in Central Brazil. Revista Brasileira de Botânica 1(1): 47-58.

Rezende, A.V.; Felfili, J. M.; Silva, P. E. N; Silva Jr., M. C. \& Silva, M. A. 1997. Comparison of gallery forests on well-drained soils on the Veadeiros Plateaux, Goiás, Brazil. Pp. 365-378. In: J. ImañaEncinas \& C. Kleinn (Eds.), Proceedings of international symposium on assessment and monitoring of forests in tropical dry regions with special reference to gallery forests, Brasília 1996. Universidade de Brasília, Brasília.
Ribeiro, J. F. \& Walter, B. M. T. 1998. Fitofisionomias do bioma Cerrado. Pp. 89-166. In: S. M. Sano \& S. P. Almeida (Eds.), Cerrado: ambiente e flora. EMBRAPA - CPAC, Planaltina, DF.

Ricklefs, R. E. 1987. Community diversity: relative roles of local and regional processes. Science 235: 167 171.

Rizzini, C. T. 1979. Tratado de fitogeografia do Brasil. HUCITEC/EDUSP, São Paulo. v.2.

Sampaio, A. B.; Nunes, R. V. \& Walter, B. M. T. 1997. Fitossociologia de uma mata de galeria na Fazenda Sucupira do CENARGEN, Brasília/DF. Pp.29-37. In: L. L. Leite, \& C. H. Saito, Contribuição ao conhecimento ecológico do Cerrado. Universidade de Brasília - Dep. de Ecologia, Brasília.

Schiavini, I. 1992. Estrutura das comunidades arbóreas de mata de galeria da estação ecológica do Panga (Uberlândia, MG). Tese de Doutorado. Universidade Estadual de Campinas, Campinas.

Silva Jr., M. C. 1995. Tree communities of the gallery forests of the IBGE Ecological Reserve, DF, Brazil. Tese de Doutorado. University of Edinburgh, Edinburgh.

Silva Jr., M. C.; Nogueira, P. E. \& Felfili, J. M. 1998. Flora lenhosa das matas de galeria no Brasil Central. Boletim do Herbário Ezechias Paulo Heringer 2: 57-76.

Walter, B. M. T. 1995. Distribuição espacial de espécies perenes em uma mata de galeria inundável no Distrito Federal; florística e fitossociologia. Dissertação de Mestrado. Universidade de Brasília, Brasília.

Walter, B. M. T. \& Ribeiro, J. F. 1997. Spatial floristic patterns in gallery forests in the Cerrado Region, Brazil. Pp. 339-349. In: J. Imaña-Encinas \& C. Kleinn (Eds.), Proceedings of international symposium on assessment and monitoring of forests in tropical dry regions with special reference to gallery forests, Brasília 1996. Universidade de Brasília, Brasília.

Walter, B. M. T. \& Sampaio, A. B. 1998. A vegetação da Fazenda Sucupira. Embrapa Recursos Genéticos e Biotecnologia, Documentos 36, Brasília.

Zar, J. H. 1996. Biostatistical analysis. Prentice Hall International Editions, London. 